\title{
Insect Bite-Like Reaction with Bullous Lesions Mimicking Bullous Pemphigoid in a Patient with Chronic Lymphocytic Leukemia
}

\author{
Jee Eun Kim, Soo-Chan Kim \\ Department of Dermatology, Gangnam Severance Hospital, Cutaneous Biology Research Institute, Yonsei University College of Medicine, \\ Seoul, Korea
}

Patients with chronic lymphocytic leukemia $(C L L)$ rarely exhibit an exaggerated insect bite-like reaction without a history of an arthropod bite. We report a case of an insect bite-like reaction in a 74-year old man with CLL. The patient presented with a 2-year history of recurrent itchy erythematous patches and blisters on the whole body. He had been diagnosed with CLL 2 years ago, and the skin lesions developed 1 month after remission. The result of a skin biopsy was consistent with insect bite. Immunohistochemical staining of the infiltrated cells showed positive reactions for CD3, CD5 and negative for CD20, CD23. Direct and indirect immunofluorescence revealed negative results. The patient was treated with oral prednisolone and dapsone, under the diagnosis of CLL-associated insect bite-like reaction, and showed marked improvement. Dermatologist should be aware of insect bite-like reaction associated with CLL as a distinct disease entity that is similar to insect bite or bullous pemphigoid. (Ann Dermatol 30(4) 468 472, 2018)

\section{-Keywords-}

B-cell chronic lymphocytic leukemia, Bullous pemphigoid, Insect bite-like reaction

Received July 25, 2017, Revised March 7, 2018, Accepted for publication March 12, 2018

Corresponding author: Soo-Chan Kim, Department of Dermatology, Gangnam Severance Hospital, 211 Eonju-ro, Gangnam-gu, Seoul 06273, Korea. Tel: 82-2-2019-3362, Fax: 82-2-2019-4881, E-mail: kimsc@yuhs.ac ORCID: https://orcid.org/0000-0002-2327-4755

This is an Open Access article distributed under the terms of the Creative Commons Attribution Non-Commercial License (http://creativecommons. org/licenses/by-nc/4.0) which permits unrestricted non-commercial use, distribution, and reproduction in any medium, provided the original work is properly cited.

Copyright (c) The Korean Dermatological Association and The Korean Society for Investigative Dermatology

\section{INTRODUCTION}

Chronic lymphocytic leukemia (CLL) is a malignant lymphoproliferative disorder characterized by progressive accumulation of leukemic cells in the blood, bone marrow, and lymphoid tissues ${ }^{1}$. Any other organ can be involved, and the skin is a common extra-nodal site for the accumulation of leukemic cells ${ }^{1}$. Skin eruptions are also common in patients with CLL, and these lesions can develop as non-specific cutaneous reactions without cutaneous infiltration of leukemic cells ${ }^{2}$.

An "exaggerated reaction to an insect bite" has been reported as a non-specific cutaneous reaction that is rarely observed in patients with $\mathrm{CLL}^{3}$. The clinical features include recurrent pruritic erythematous patches, papules, plaques, and bullae, which are similar to the clinical features of insect bites or autoimmune bullous diseases ${ }^{2}$. However, the reactions have been described as "insect bite-like reactions" or "eosinophilic eruption of hematoproliferative diseases" because the lesions are often triggered without a preceding arthropod bite ${ }^{2}$. We report a case of an insect bite-like reaction with bullous lesions in a 74-year-old man with CLL. The study was approved by the Institutional Review Board of the Gangnam Severance Hospital (IRB no. 3-2016-0273). Informed consent was obtained from the patient prior to this report. We received the patient's consent form about publishing all photographic materials.

\section{CASE REPORT}

A 74-year-old an presented with a 2-year history of pruritic recurrent erythematous patches and bullae on the whole body. The patient had been diagnosed with CLL in 2015. 
Immunophenotyping with the bone marrow biopsy showed positive for CD5, CD20, CD23 in leukemic cells. He had achieved complete remission after 2 months of chemotherapy with chlorambucil, fludarabine, cyclophosphamide, and rituximab. The skin lesions developed 1 month after the complete remission of CLL. The skin lesions had responded to oral methylprednisolone, but tended to relapse with tapering of methylprdnisolone, and the patient experienced worsening of the lesions and itching sensation 6 months before his presentation. A physical examination revealed erythematous patches and bullae on the whole body (Fig. 1), and we suspected a diagnosis of bullous pemphigoid. Laboratory test revealed an elevated eosinophil count $(26.6 \%, 2,020 / \mu \mathrm{l})$. Skin biopsy at the right knee revealed mild spongiosis of the epidermis, subepidermal bulla, and edema at the papillary dermis. Lymphocytic infiltration with eosinophils was found throughout the dermis and subcutaneous fat layer (Fig. 2). Immunohistochemical staining of the infiltrated cells showed positive reactions for CD3, CD5 and negative for CD20, CD23 (Fig. 3). Direct and indirect immunofluorescence revealed negative results. The diagnosis of CLLassociated insect bite-like reactions was made based on the histopathological features and immunofluorescence results.

The skin lesions resolved 3 months after treatment with oral methylprednisolone (8 $12 \mathrm{mg})$, dapsone (50 mg) and topical diflucortolone valerate. The patient has remained in remission with low-dose methylprednisolone $(4 \mathrm{mg}$ ) and dapsone (25 mg) during a 6-month follow-up.

\section{DISCUSSION}

In 1965, Weed $^{3}$ first reported an exaggerated reaction to an insect bite in a patient with CLL, who developed induration, edema, erythema, and bullae with intense pruritus at the site of the insect bite. He suggested that this reaction was a delayed hypersensitivity reaction to the insect bites, based on the patient's altered immune response caused by the $\mathrm{CLL}^{3}$. However, more recent studies have frequently reported insect bite-like reactions in patients with CLL without the patient's recalling an insect bites ${ }^{2}$. Furthermore, the lesions were often not restricted to exposed sites and did not exhibit seasonal variations, which indicate that the lesions might not be triggered by an insect bite ${ }^{2}$. Barzilai et al. ${ }^{4}$ have suggested the term "insect bite-like reaction" for this phenomenon, which was further defined as "eosinophilic dermatosis of myeloproliferative disease" by Byrd et al. ${ }^{5}$ These authors also proposed diagnostic criteria: (1) pruritic papules, nodules, and/or vesiculobullous eruptions that were resistant to conservative management; (2) histopathologically confirmed eosinophil-rich dermal lymphohistiocytic infiltration at the superficial and deep dermis; (3) exclusion of other causes of tis-
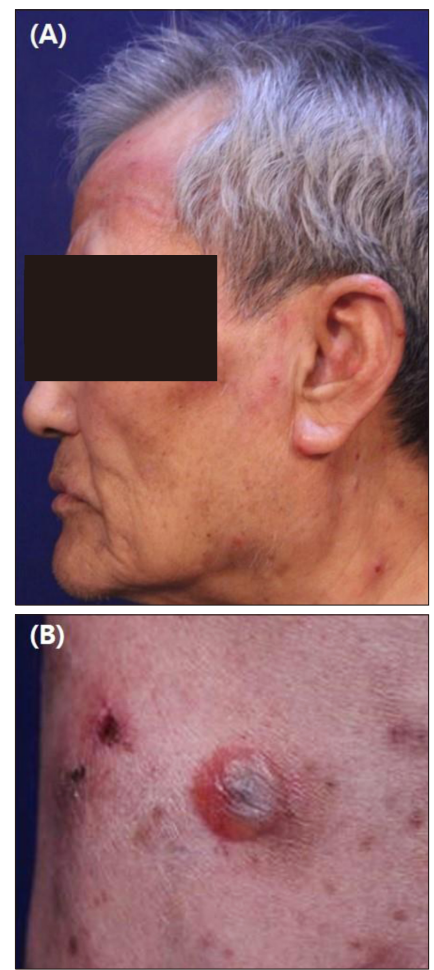

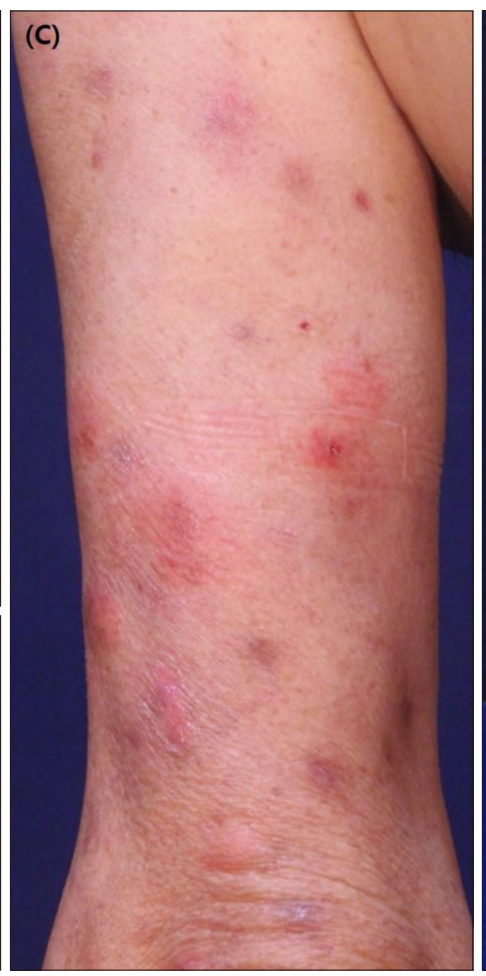

Fig. 1. Clinical features of the patient. (A, C, D) Erythematous excoriated papules, patches and vesicles on the face and extremities. (B) Flaccid bulla on the left leg. 


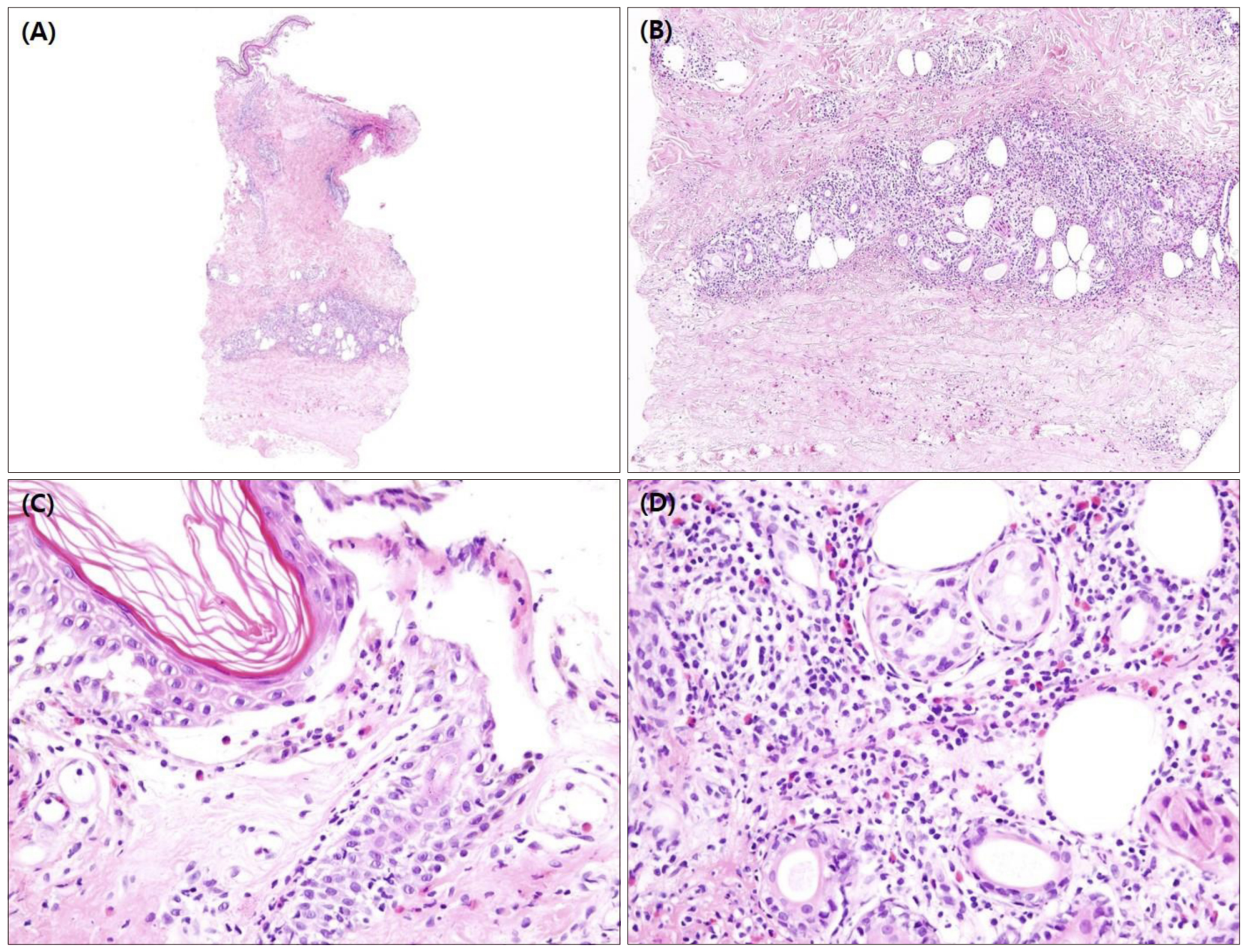

Fig. 2. Histologic features of the skin biopsy. (A) Subepidermal bulla and inflammatory cell infiltration on the dermis and subcutaneous layer $(\mathrm{H} \& \mathrm{E}, \times 40)$. (B, D) Inflammatory cell infiltration of lymphocytes and eosinophils on the deep dermis and subcutaneous layer (B: H\&E, $\times 100, D: H \& E, \times 400)$. (C) Subepidermal separation and inflammatory cell infiltration of lymphocytes and eosinophils in the bulla $(\mathrm{H} \& \mathrm{E}, \times 400)$.

sue eosinophilia; and (4) a pre-existing diagnosis of a hematological malignancy ${ }^{5}$. Insect bite-like reaction with bullous eruption shows similar clinical and histologic features of bullos pemphigoid. Thus, direct and indirect immunofluorescence examinations are mandatory to make correct diagnosis.

The pathogenesis of insect bite-like reactions remains unclear. The skin lesions have been considered as a non-specific cutaneous reaction to certain stimuli in patients with hematologic diseses, not a specific reaction by leukemic cells. A recent study using in situ hybridization analysis demonstrated that neoplastic CLL cells were observed within insect bite-like skin lesions, suggesting they may be specific skin lesions, rather than non-specific cutaneous skin reactions ${ }^{6,7}$. In our case, immunohistochemical stain showed negative for CD20 and CD 23 in skin, which are highly expressed in neoplastic CLL cells and also de- tected in our patient's bone marrow biopsy, indicating that the lesions are not related to skin infiltrates of the neoplastic CLL cells ${ }^{8}$. In fact, insect bites, drugs, chemoimmunotherapy, and pyogenic infections can trigger non-specific eosinophilic eruptions in patients with $\mathrm{CLL}^{2}$. The altered immune response in patients with hematological disease can increase the secretion of interleukin 4 (IL-4) and IL-5, which stimulates eosinophilic skin infiltration ${ }^{4}$.

The development of skin lesions are usually not related with the course or activity of CLL as our case ${ }^{2}$. Bairey et al. $^{2}$ have reported that the skin eruptions can occur before diagnosis of CLL or after the end of chemotherapy. Oral glucocorticoids, intravenous immunoglobulin, and dapsone have been reported to be effective for controlling the lesions ${ }^{4,9}$. Re-initiation of chemotherapy may also help improve the skin lesions in some of patients ${ }^{10}$. Our patient showed remarkable improvement after receiving combina- 

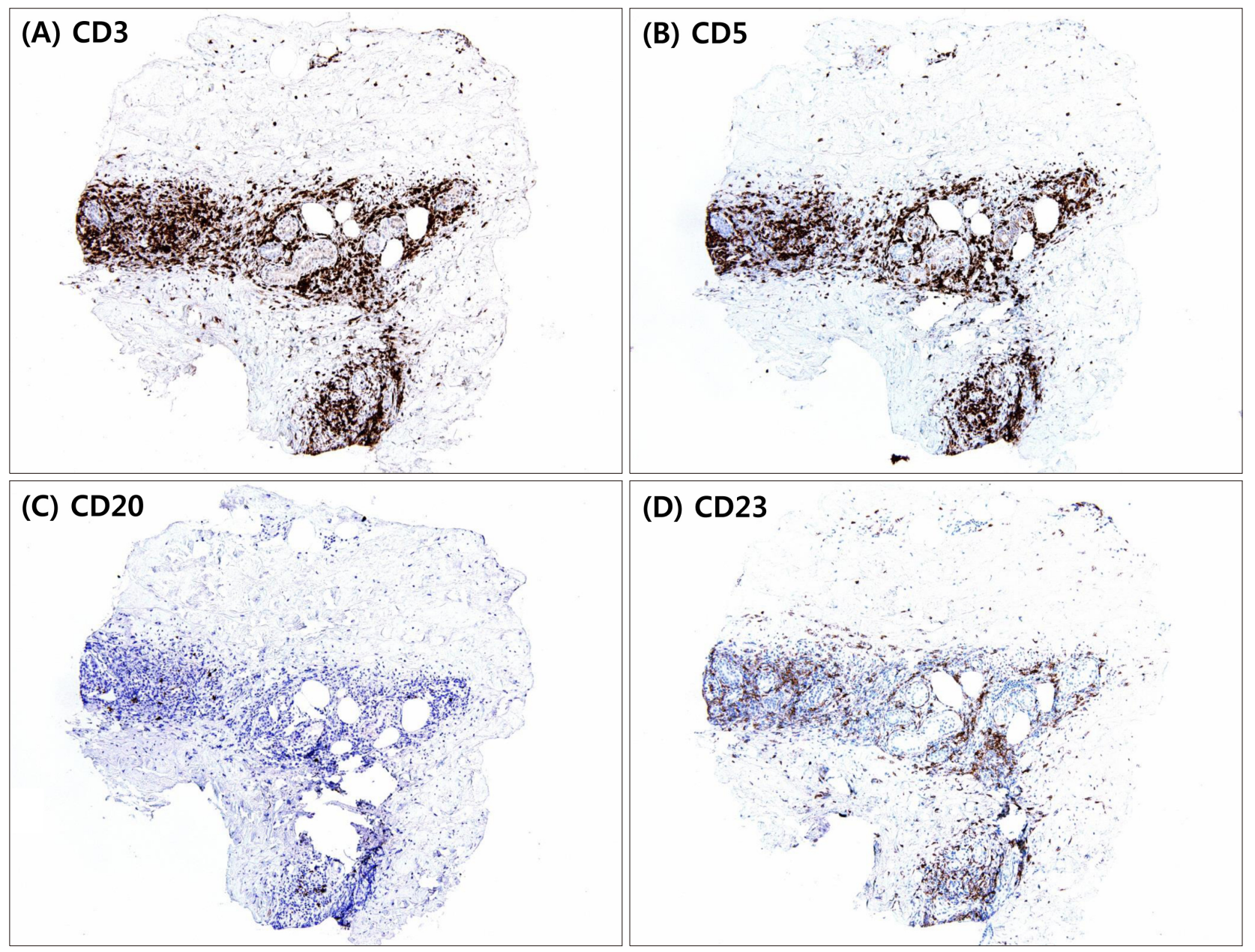

Fig. 3. The immunohistochemical stains were positive for $(A) C D 3(\times 100)$ and $(B)$ CD5 $(\times 100)$, while the immunohistochemical stains were negative for $(C)$ CD20 $(\times 100)$ and $(D)$ CD23 $(\times 100)$.

tion therapy with oral methylprednisolone and dapsone. In conclusion, insect bite-like reaction with bullous lesions should be considered, particulary when a patient with CLL shows chronic insect bite-like or bullous pemphigoid-like lesions.

\section{CONFLICT OF INTEREST}

The authors have nothing to disclose.

\section{REFERENCES}

1. Wierda WG, Zelenetz AD, Gordon LI, Abramson JS, Advani $\mathrm{RH}$, Andreadis $\mathrm{CB}$, et al. NCCN guidelines insights: chronic lymphocytic leukemia/small lymphocytic leukemia, version 1.2017. J Natl Compr Canc Netw 2017;15:293-311.

2. Bairey O, Goldschmidt N, Ruchlemer R, Tadmor T, Rahimi-Levene $N$, Yuklea $M$, et al. Insect-bite-like reaction in patients with chronic lymphocytic leukemia: a study from the Israeli chronic lymphocytic leukemia study group. Eur J Haematol 2012;89:491-496.

3. Weed RI. Exaggerated delayed hypersensitivity to mosquito bites in chronic lymphocytic leukemia. Blood 1965;26:257268.

4. Barzilai A, Shpiro D, Goldberg I, Yacob-Hirsch Y, Diaz-Cascajo C, Meytes D, et al. Insect bite-like reaction in patients with hematologic malignant neoplasms. Arch Dermatol 1999;135:1503-1507.

5. Byrd JA, Scherschun L, Chaffins ML, Fivenson DP. Eosinophilic dermatosis of myeloproliferative disease: characterization of a unique eruption in patients with hematologic disorders. Arch Dermatol 2001;137:1378-1380.

6. Mitteldorf C, Tronnier M, Merz H, Haenssle HA, Bertsch $\mathrm{HP}$, Schön MP, et al. Insect bite-like reactions in a patient with B-cell chronic lymphocytic leukaemia: fluorescence in situ hybridization analysis revealed neoplastic B cells within the skin infiltrate. Br J Dermatol 2012;167:944-946.

7. Butzmann CM, Kern JS, Stanislawski G, Meiss F. Insect bite-like reaction in a patient with chronic lymphocytic leukemia. J Dtsch Dermatol Ges 2014;12:734-737. 
8. Robak E, Robak T. Skin lesions in chronic lymphocytic leukemia. Leuk Lymphoma 2007;48:855-865.

9. Ulmer A, Metzler G, Schanz S, Fierlbeck G. Dapsone in the management of "insect bite-like reaction" in a patient with chronic lymphocytic leukaemia. Br J Dermatol 2007;156: 172-174.
10. Davis MD, Perniciaro C, Dahl PR, Randle HW, McEvoy MT, Leiferman KM. Exaggerated arthropod-bite lesions in patients with chronic lymphocytic leukemia: a clinical, histopathologic, and immunopathologic study of eight patients. J Am Acad Dermatol 1998;39:27-35. 